\title{
COVID-19 with Stigma: Theory and Evidence from Mobility Data
}

\author{
Yuya Katafuchi ${ }^{1} \cdot K$ Kenichi Kurita ${ }^{2} \cdot$ Shunsuke Managi ${ }^{2}$
}

Received: 5 August 2020 / Accepted: 31 August 2020 / Published online: 21 September 2020 (C) Springer Nature Switzerland AG 2020

\begin{abstract}
This study conducts both theoretical and empirical analyses of how non-legally-binding COVID-19 policies affect people's going-out behavior. The theoretical analysis assumes that under a declared state of emergency, the individual going out suffers psychological costs arising from both the risk of infection and the stigma of going out. Our hypothesis states that under a declared state of emergency people refrain from going out because it entails a strong psychological cost. Then, this study estimates a model using regional mobility data and emergency declarations data to analyze self-restraint behavior under a non-legally binding emergency declaration. The results show that, compared with before the declaration of the state of emergency, going-out behavior was suppressed under the state of emergency and after it was lifted even when going out did not result in penalties, which is consistent with the theoretical analysis.
\end{abstract}

Keywords COVID-19 · Stigma - Self-restraint behavior · Non-legally binding policy · Regional mobility

This article is part of the Topical Collection on Economics of COVID-19

The authors acknowledge the support from JSPS KAKENHI grant numbers JP19K23194 and JP20K13486, and of Feasibility Project 14200138 of Research Institute for Humanity and Nature. We should like to thank editors of Economics of Disasters and Climate Change as well as anonymous reviewers. We also appreciate valuable comments from Keisuke Hattori, Kosuke Hirose, and Jumpei Hamamura.

Yuya Katafuchi

katafuchi@chikyu.ac.jp

Kenichi Kurita

kurita.kenichi.564@m.kyushu-u.ac.jp

Shunsuke Managi

managi@doc.kyushu-u.ac.jp

1 Research Institute for Humanity and Nature, 457-4 Motoyama, Kamigamo, Kita-ku, Kyoto 603-8047 Japan

2 Urban Institute and Department of Civil Engineering, School of Engineering, Kyushu University, 744 Motooka, Nishi-ku, Fukuoka 819-0395 Japan 


\section{Introduction}

The coronavirus disease of 2019 (COVID-19) has become a global pandemic that has infected more than 21 million people worldwide as of August 16, 2020 (WHO 2020). To reduce its spread, countries around the world have adopted a variety of policies. In particular, strong policy measures to reduce infection have been implemented to restrict people's activities, especially their ability to go out, in an effort to reduce their chances of contact. Other policies have also been applied globally to protect people, such as social distancing, stay home, school closure, and protection measures at ports and airports. Yoo and Managi (2020) argue that such policies against COVID-19 will save lives and consequently minimize economic losses. Furthermore, Nakamura and Managi (2020) show that reducing air travel decreases the risk of the import and export of goods. Policies that restrict behavior with the aim of preventing the spread of infectious diseases can be categorized into two types: enforceable behavioral restrictions that consider penalties using the legal system, and behavioral restrictions that do not use the legal system and are left to people's sense of self-restraint (unenforceable).

Examples of the former are the behavioral limitations imposed by the policies of several European countries where the COVID-19 infection had spread rapidly. Under the Health Emergency Bill approved by lawmakers on March 22, 2020, France imposes fines of between 135 and 3,700 Euros on people going out for purposes other than those authorized by the government such as the purchase of daily necessities. In Italy, which has the world's sixth-highest number of COVID-19-related deaths at 35,392 (as of August 16, 2020), a decree ordered a nationwide curfew on March 10, 2020, with fines of up to 3,000 Euros for those who do not carry a "certificate" stating where they are going and why. As of August 16, 2020, the United States has the highest number of cases in the world. With the highest number of cases in the country, New York State issued a governor's decree on March 22, 2020, requiring $100 \%$ telecommuting. The decree imposes fines of up to 10,000 dollars if a company fails to comply and causes serious physical harm to its employees.

In contrast to these strict measures against the spread of infectious diseases that prohibit citizens from going out where the state imposes severe private rights restrictions with penalties for violations, the legal basis for restricting behavior in several other countries is vague. This refers to the second type of policy described above-a policy of curtailment based on people's self-restraint, without enforcement. Aiming to attain a certain number of infections and immunization without strict restrictive measures, Sweden recommends working from home and only advocates avoiding unnecessary travel and social contact with highrisk older people. Japan, which has the lowest number of cases per million people among the 36 industrialized countries in the OECD, has a non-coercive, unenforceable policy with a vague legal basis, such as declaring a state of emergency and requesting that people refrain from leaving home unnecessarily to control the spread of COVID-19.

Japan's policy resulted in a reduction in going-out behavior after the declaration of the state of emergency (The Japan Times 2020a; Kyodo News 2020). Thus, the number of infections is considered to have been controlled more successfully than in other OECD countries (Lu et al. 2020; Iwasaki and Grubaugh 2020). However, although these reports of reduced going-out behavior compare such behavior before and after the emergency declaration, they only focus on densely populated central metropolitan areas and do not control for public awareness of the increase in the number of infections and the behavior reflected by it. Therefore, it is not possible to conclude from these reports whether the declaration of emergency actually reduced the amount of going-out behavior across the country, that is, the entire area within which the request for self-restraint was made. 
In fact, the effect of these requests for self-restraint on the public's consciousness in Japan is reflected in the "self-restraint police" (Jishuku Keisatsu in Japanese) phenomenon. The self-restraint police are said to be members of the general public who conduct private policing of individuals and groups who do not comply with requests to refrain from going out or other activities under the emergency declaration. There have been incidents involving these self-restraint police, such as harassing phone calls, posts about restaurants that were operating under the declared state of emergency (The Japan Times 2020c), slander of travelers because of their history of having COVID-19 (The Japan Times 2020b), and damage to travelers' cars at tourist sites when the license plate numbers indicated that the cars were from another prefecture (The Japan Times 2020b).

It is likely that this phenomenon occurred because people have an aversion to those who do not refrain from going out, even in the case of the non-legally binding declaration of a state of emergency. Thus, we suggest that even under unenforceable policies, people may refrain from going out to avoid the social stigma. Accordingly, this study focuses on restrictions that inhibit people from going out under a decree that has an ambiguous legal basis, from both the theoretical and empirical perspectives.

Specifically, for the theoretical analysis, we introduce a theoretical model that analyzes self-restraint behavior in the context of spreading infectious diseases from the stigmatization perspective. First, statements such as the Japanese government's state of emergency are not legally binding. Thus, there are no fines or penalties for individuals who go out. Nevertheless, most Japanese citizens refrained from going outside under the state of emergency. A plausible reason for the declaration's success is that most people were afraid of the risk of infection at that time. For example, Aum et al. (2020) assume that people accept the disutility of going out because of the risk of infection and conclude that people will stay home if they are at high risk of infection. If this is the only reason, then the effect of restraint should be consistent when the risk of infection is constant under the state of emergency and after it is lifted. Could this be true? What must other important factors be considered that affect people's self-restraint behavior? To address these questions, we analyze people's self-restraint behavior by introducing stigma into our theoretical model, as well as the risk of infection.

The research on stigma has developed around social psychology Major et al. (2018), starting with the discussion by Goffman (1963). There are also several studies on stigma in economics; Moffitt (1983), Besley and Coate (1992), and Bhargava and Manoli (2015) study the stigma of accepting welfare benefits (Lindbeck et al. 1999; Kurita et al. 2020; Itaya and Kurita 2020). Moreover, Kim (2003) analyzes the stigma related to tax evasion, and Rasmusen (1996) investigates the stigma against an ex-convict.

Stigma is important in analyzing the going-out behavior during the spread of infectious diseases because it can play a complementary role to infection risk in people's self-restraint behavior. In Japan, under the state of emergency, it was a social norm to refrain from going out. Public opinion was that going out under the state of emergency was anti-social behavior. In other words, people who go out under the state of emergency are stigmatized by society as having inferior ethics because they do not follow the social norms.

The theoretical analysis in this study assumes that, under the declared state of emergency, the individual going out suffers psychological costs arising from both the stigma of going out and the risk of infection. That is, we emphasize that infection risk and stigma have a complementary effect on the psychological cost to the player. Thus, the theoretical result shows that under a declared state of emergency, people refrain more from going out as it entails a strong psychological cost.

For the empirical perspectives, several studies analyze the effect of Japan's non-legally enforceable emergency declarations on the population. For example, Kobayashi et al. (2020) 
use a state-space model that combines susceptible-infected-recovered models to predict the evolution of infectious diseases and includes the magnitude and timing of the peak of the epidemic, following the emergency declaration in Japan. They confirm that the issuance and extension of the state of emergency declaration has, to some extent, been successful in controlling the COVID-19 pandemic. Based on a survey of areas where the spread of COVID-19 infection was significant, Yamamoto et al. (2020) show that actions of self-restraint based on the declaration of a state of emergency cause psychological distress. Kawaguchi et al. (2020) use data from small and medium-sized Japanese enterprises to find that, in the short term, the state of emergency reduces both feasible and expected sales. Qian and Yahara (2020) conduct a survey under the state of emergency and find that accuracy, morality, and ideology are changing people's behavior and mental health in response to COVID-19. Finally, Yamamura and Tsutsui (2020) analyze individual-level changes in preventive behavior and mental status due to the emergency declaration.

In contrast to studies analyzing the effect of non-legally binding policies such as those described above, others analyze the effect of an enforceable lockdown on the economy (Acemoglu et al. 2020; Alvarez et al. 2020; Farboodi et al. 2020; Holtemöller 2020; Eichenbaum et al. 2020; Gharehgozli et al. 2020; Mandel and Veetil 2020; Martin et al. 2020). Martin et al. (2020) develop a microeconomic model to assess the socioeconomic effect of COVID-19 on individuals, estimating the direct effect of the lockdown policy on household income, consumption, and poverty. Acemoglu et al. (2020) build a heterogeneous susceptible-exposed-infected-recovered model and conclude that a lockdown policy that focuses on at-risk older groups is optimal. Alvarez et al. (2020) discuss the optimal lockdown policy to minimize the deaths and economic costs attributable to COVID-19, using the formulation as an optimization problem. Mandel and Veetil (2020) estimate the costs of a lockdown due to COVID-19 in some sectors of the global economy using a multi-sector disequilibrium model that considers the buyer-seller relationship between agents in different countries. However, none consider stigma in their scope of research. In addition, lockdowns, unlike emergency declarations, have a legal basis with penalties. In other words, they do not consider the effects of looser emergency declarations that are not legally binding.

Based on the above research, this study contributes in the following ways: First, it develops a microeconomic theoretical model of people's going-out behavior in non-legally binding emergency declarations considering the social stigma against going out. Second, we estimate a macro-panel data model that combines daily data on various outside behaviors covering all prefectures in Japan that were collected pre-declaration, under declaration, and post-declaration, as well as covariates to control for various confounding factors. We thus measure the effect of emergency declarations on the behavior of people outside the area simultaneously considering factors that contribute to their behavior and the heterogeneity of emergency declarations in different areas with different dates of issuance. In addition, we compared the behavior of people who went out after the emergency declaration was lifted with that before the declaration.

The advantages of our contribution over existing studies on non-legally binding emergency declarations are as follows: First, there is little analysis in the literature on going-out actions associated with the issuance of emergency declarations based on ambiguous legal systems. Second, we build a theoretical model to explain going-out behavior under nonlegally binding emergency declarations based on social stigma. Although Yamamura and Tsutsui (2020) analyze people's going-out behavior under a state of emergency in Japan, because their data set is based on an online questionnaire survey, there is a possibility of measurement error due to personal memory differences and other factors. Moreover, because their study used a sample composed of two time points-before and after the 
declaration of an emergency-they did not consider changes in going-out activity after the lifting of the state of emergency. By contrast, this study conducts an empirical analysis considering the three time points of pre-declaration, under declaration, and post-declaration using data obtained from Google COVID-19 Community Mobility Reports, which provide more objective data than questionnaire survey data.

In the following, we summarize our results. The theoretical analysis showed that the stigmatization of going-out behavior reduces the incentive to go out under the state of emergency compared with that after it is lifted. In other words, the number of people who go out under the state of emergency is lower than that after the emergency is lifted. Second, in the empirical analysis, we examined going-out behavior under a declared state of emergency using daily mobility data for 47 prefectures in Japan. After controlling for confounding factors that may vary by prefecture and time, we find that going-out behavior is decreased under the state of emergency and after it lifted. Furthermore, this study finds that going-out behavior decreased the most during the under declaration period.

The remainder of this paper is organized as follows: In Theoretical Model, we present the theoretical analysis. Empirical Analysis discusses the data, econometric methods, and analytical results. Finally, Conclusion concludes.

\section{Theoretical Model}

\section{Setting and Equilibrium}

Consider an economy in which the mass of the population is normalized to 1 . The player chooses to go out or not. The player's payoff is set as follows:

$$
\begin{cases}u_{\text {out }}-\phi[\gamma c+\iota \sigma s]^{\delta} & \text { if going out, } \\ u_{\text {home }} & \text { if staying home, }\end{cases}
$$

where $u_{\text {out }}$ is the utility from going out and $u_{\text {home }}$ is the utility from staying home. We assume that the utility from going out is higher than that from staying home, that is, $u_{\text {out }}>$ $u_{\text {home }}$.

$\phi[\gamma c+\iota \sigma s]^{\delta}$ is the term of the psychological cost. This cost contains the two components of the risk of infection $(\gamma c)$ and the stigma $(\iota \sigma s)$. This formulation indicates that the stigma and the risk of infection are complementary in the psychological cost. Here, $\phi \in[0, \bar{\phi}]$ is the sensitivity to the psychological cost, $\gamma \in[0,1]$ is the subjective probability of an individual being infected after going out, $c$ is the cost of infection, $s$ is the stigma cost, $\sigma \in(0,+\infty)$ is a parameter that indicates the relative size of the stigma to the infection in the psychological cost, $\delta \in(0,+\infty)$ is the parameter of cost to scale, and $\iota \in\{0,1\}$ is an indicator variable that equals one if a state of emergency is declared and zero otherwise.

We assume that $\phi$ has the distribution $\phi \sim F(\cdot)$, where $F^{\prime}(\cdot):=f(\cdot)$ and $f(\phi)>0$ for $\phi \in[0, \bar{\phi}]$. Then, we consider the critical level of the sensitivity to the stigma cost as follows:

$$
u_{\text {out }}-\hat{\phi}[\gamma c+\iota \sigma s]^{\delta}=u_{\text {home }} .
$$

From Equation (2), individuals with sensitivities below (above) this threshold have an incentive to go out (stay home). Solving for $\hat{\phi}$, we obtain the following:

$$
\hat{\phi}=\frac{\Delta}{[\gamma c+\iota \sigma s]^{\delta}},
$$


where $\Delta:=u_{\text {out }}-u_{\text {home }}>0$

The proportion of individuals who go out, $x$, is expressed as follows:

$$
x=\operatorname{Pr}(\phi \leq \hat{\phi})=F(\hat{\phi}) .
$$

We suppose that the stigma cost function is based on conformism as in Lindbeck et al. (1999) and Lindbeck et al. (2003). We assume that the stigma cost decreases with the proportion of individuals who go out, that is, $s=s(x), s^{\prime}(x)<0$, and $s \in(0,+\infty)$

We also assume that the difference of utility is higher than the expected cost of infection, that is, $\Delta>\gamma c$. When $\iota=0$, all individuals choose to go out because $u_{\text {out }}>u_{\text {home }}$. By contrast, the case of $\iota=1$ is analyzed as follows:

$$
\begin{gathered}
\left\{\begin{array}{l}
\hat{\phi}=\frac{\Delta}{[\gamma c+\iota \sigma s]^{\delta}}, \\
x=F(\hat{\phi}), \\
s=s(x),
\end{array}\right. \\
x=F\left(\frac{\Delta}{[\gamma c+\iota \sigma s(x)]^{\delta}}\right):=\chi(x) .
\end{gathered}
$$

The fixed point of Equation (6), $x^{*}$, is the equilibrium of this model ${ }^{1}$. Clearly, there is at least one equilibrium from the intermediate value theorem. We present the following proposition:

Proposition 1 There can be multiple equilibria under a state of emergency. Conversely, there is a unique equilibrium when the state of emergency is lifted as follows:

$$
x_{\text {post }}^{*}=F\left(\frac{\Delta}{(\gamma c)^{\delta}}\right) \text {. }
$$

Proof The slope of Equation (6) is given as follows:

$$
\frac{\partial \chi}{\partial x}=f\left(\frac{\Delta}{[\gamma c+\iota \sigma s(x)]^{\delta}}\right)\left[\frac{\Delta \delta}{[\gamma c+\iota \sigma s(x)]^{\delta+1}}\right]\left[-\iota \sigma s^{\prime}(x)\right]>0 .
$$

There is the possibility of multiple equilibria under a state of emergency because the sign of Equation (8) is positive.

By contrast, the sign of Equation (8) is zero when the state of emergency is lifted. To confirm the equilibrium when the state of emergency is lifted, we substitute $\iota=0$ into Equation (6) and obtain the following result:

$$
\left.\chi(x)\right|_{\iota=0}=F\left(\frac{\Delta}{(\gamma c)^{\delta}}\right) .
$$

Equation (9) is fixed with respect to $x$. Therefore, the equilibrium when the state of emergency is lifted $\left(x_{\text {post }}^{*}\right)$ is unique and is expressed as follows:

$$
x_{\text {post }}^{*}=F\left(\frac{\Delta}{(\gamma c)^{\delta}}\right) \text {. }
$$

\footnotetext{
${ }^{1}$ The stability condition for the equilibrium is $\partial \chi / \partial x<1$.
} 
Proposition 1 suggests the possibility of multiple equilibria displayed in Fig. 1 as an example. This figure shows $\chi(x):\left.\chi(x)\right|_{\iota=1}$ or $\left.\chi(x)\right|_{\iota=0}$, where $\left.\chi(x)\right|_{\iota=1}$ is $\chi(x)$ under a state of emergency and $\left.\chi(x)\right|_{\iota=0}$ is $\chi(x)$ after a state of emergency. There are two equilibria, one with very few people going-out $\left(x_{\mathrm{under} ; \mathrm{L}}^{*}\right)$ and one with many people going-out $\left(x_{\text {under; } H}^{*}\right)$, as multiple equilibria under the state of emergency in Fig. 1. We call $x_{\text {under; } \mathrm{L}}^{*}$ the "strictly self-restraint equilibrium" and $x_{\mathrm{under}, \mathrm{H}}^{*}$ the "non-strictly selfrestraint equilibrium." The reason for this is the existence of the complementarity that arises from the presence of externalities between people's behavior under the state of emergency. We can consider that in the Japanese case, under the emergency declaration, an equilibrium with fewer people going out was achieved-that is, the strictly selfrestraint equilibrium, $x_{\text {under; }}^{*}$ - and after the emergency declaration, social norms were no longer in effect-that is, the non-strictly self-restraint equilibrium, $x_{\text {post }}^{*}$. By contrast, the Florida case could be deemed to fall under $x_{\text {under; } \mathrm{H}}^{*}$ (BBC 2020; Bloomberg 2020). In Florida under the declaration of the state of emergency, we can assume that an equilibrium was achieved in which many people did not choose to act with restraint.

In the game with multiple equilibria, it is generally not possible to know a priori which equilibrium will actually be realized as is well known in economics and game theory. Therefore, it is likely that we would need to revise non-legally binding policies in favor of more legally binding policies to achieve a more accurate policy outcome in the fight against COVID-19.

The following proposition presents the results for the difference in the number of citizens going out between the under the declaration of the state of emergency and after its lifting.

Proposition 2 The equilibrium proportion of players going out under the state of emergency $\left(x_{\text {under }}^{*}\right)$ is less than those going out after it was lifted ( $x_{\text {post }}^{*}$ ), ceteris paribus.

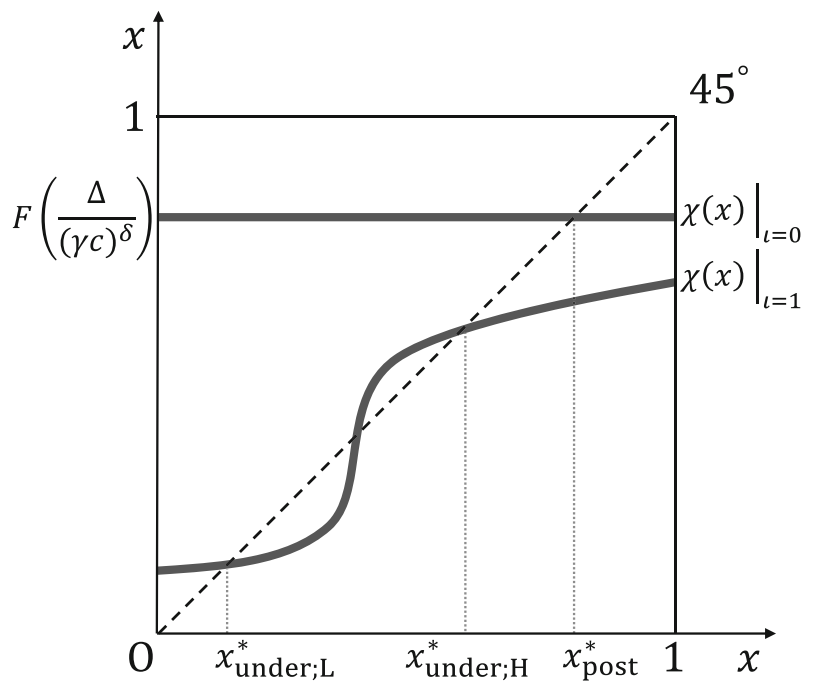

Fig. 1 Example of multiple equilibria 
Proof Under the state of emergency $(\iota=1)$, by substituting $\iota=1$ into (6), we obtain the following:

$$
\left.\chi(x)\right|_{\iota=1}=F\left(\frac{\Delta}{[\gamma c+\sigma s(x)]^{\delta}}\right) .
$$

We denote the fixed point of Equation (11) as $x_{\text {under }}$.

After the state of emergency is lifted, by substituting $\iota=0$ into (6), we obtain the following:

$$
\left.\chi(x)\right|_{\iota=0}=F\left(\frac{\Delta}{(\gamma c)^{\delta}}\right) .
$$

We denote the fixed point of Equation (12) as $x_{\text {post }}$.

The difference between Equations (11) and (12) is given as follows:

$$
\left.\chi(x)\right|_{\iota=1}-\left.\chi(x)\right|_{\iota=0}<0 .
$$

Therefore, we obtain the following result:

$$
x_{\text {under }}^{*}-x_{\text {post }}^{*}<0
$$

for any $x \in[0,1]$.

Proposition 2 shows that even in the condition with a fixed subjective probability of infection, the number of people going out under a request for self-restraint based on the declaration of a state of emergency is lower than those going out after the state of emergency is lifted. This implies that a non-legally binding policy - the state of emergency-can influence going-out behavior through stigmatization regardless of the fear of infection. Figure 1 shows that $\left.\chi(x)\right|_{\iota=1}$ is never above $\left.\chi(x)\right|_{\iota=0}$. That is, we confirm the relationship of, $x_{\text {post }}^{*}>x_{\text {under; } \mathrm{H}}^{*}>x_{\text {under; } \mathrm{L}}^{*}$.

The following proposition presents an interesting result.

Proposition 3 Under the state of emergency, that is, $\iota=1$, some players restrain themselves from going out, even if all players expect the probability of infection to be zero, that is, $\gamma=0$.

Proof By substituting $\iota=1$ and $\gamma=0$ into Equation (6), we obtain the following:

$$
\left.\chi(x)\right|_{\iota=1, \gamma=0}=F\left(\frac{\Delta}{[\sigma s(x)]^{\delta}}\right) .
$$

The sign of Equation (15) is positive because $\Delta>0, \sigma>0$, and $s(x)>0$ for any $x \in[0,1]$. Therefore, the fixed point of Equation (15) is positive, that is, $x_{\text {under }}^{*}>0$.

Proposition 3 suggests that some individuals refrain from going out even if they all think that the probability of infection is zero under the emergency declaration. This suggests that even in the absence of the fear of infection, non-legally binding emergency declarations can influence behavior through stigmatization.

This section describes the theoretical analysis of individual behavior in situations where there are infection risk and psychological cost due to the stigma of going out. We show that requests for self-restraint against going out based on non-legally binding emergency declarations are in effect in equilibrium. Notably, Proposition 3 suggests that non-legally binding emergency declarations also affect the behavior of players through stigmatization even in 
the condition with a fixed subjective probability of infection. In the following empirical analysis, we examine the results of Proposition $2^{2}$.

\section{Comparative Static Analysis}

To investigate the effects of a change in each parameter $\left(u_{\text {out }}, u_{\text {home }}, \gamma, c, \sigma\right.$, and $\left.\delta\right)$ on the equilibrium proportion of players going out, we conduct a comparative static analysis. Results are summarized in the following proposition:

Proposition 4 Results in the comparative static analysis are given as follows:

1. An increase in the utility from going out raises the population of players going out in the equilibrium under the state of emergency and after its lifting.

2. An increase in the utility from staying home reduces the population of players going out in the equilibrium under the state of emergency and after its lifting.

3. An increase in the subjective probability of an individual being infected after going out reduces the population of players going out in the equilibrium under the state of emergency and after its lifting.

4. An increase in the cost of infection reduces the population of players going out in the equilibrium under the state of emergency and after its lifting.

5. An increase in the relative size of the stigma to the infection in the psychological cost reduces the population of players going out in the equilibrium under the state of emergency whereas it does not affect it after the lifting.

6. An increase in the level of the parameter of cost to scale reduces the population of players going out in the equilibrium under the state of emergency and after its lifting.

Proof First, we conduct the comparative static analysis in the equilibrium under the state of emergency. Let us consider the effect of an increase in the level of the utility from going out, $u_{\text {out }}$, on the equilibrium under the state of emergency, $x_{\text {under }}^{*}$. By the implicit function theorem, we get the following result:

$$
\frac{d x_{\mathrm{under}}^{*}}{d u_{\mathrm{out}}}=\frac{\frac{\left.\partial \chi(x)\right|_{\iota=1}}{\partial u_{\mathrm{out}}}}{1-\frac{\left.\partial \chi(x)\right|_{\iota=1}}{\partial x}},
$$

because:

$$
\frac{\left.\partial \chi(x)\right|_{\iota=1}}{\partial u_{\text {out }}}=f\left(\frac{\Delta}{[\gamma c+\sigma s(x)]^{\delta}}\right)>0,
$$

and $\left.\partial \chi(x)\right|_{l=1} / \partial x<1$ from the stability condition.

The effect of an increase in the level of the utility from staying home, $u_{\text {home}}$, on the equilibrium under the state of emergency, $x_{\text {under }}^{*}$, is given by:

$$
\frac{d x_{\text {under }}^{*}}{d u_{\text {home }}}=\frac{\frac{\left.\partial \chi(x)\right|_{\iota=1}}{\partial u_{\text {home }}}}{1-\frac{\left.\partial \chi(x)\right|_{\iota=1}}{\partial x}}<0,
$$

\footnotetext{
${ }^{2}$ Proposition 3 analyzes going-out behavior under the subjective infection probability of zero. However, because it is difficult to verify a situation wherein the subjective infection probability is zero in the real world, only Proposition 2 is tested in the empirical analysis.
} 
because:

$$
\frac{\left.\partial \chi(x)\right|_{\iota=1}}{\partial u_{\text {home }}}=-f\left(\frac{\Delta}{[\gamma c+\sigma s(x)]^{\delta}}\right)<0 .
$$

The effect of an increase in the subjective probability of an individual being infected after going out, $\gamma$, on the equilibrium under the state of emergency, $x_{\text {under }}^{*}$, is given by:

$$
\frac{d x_{\mathrm{under}}^{*}}{d \gamma}=\frac{\frac{\left.\partial \chi(x)\right|_{\iota=1}}{\partial \gamma}}{1-\frac{\left.\partial \chi(x)\right|_{\iota=1}}{\partial x}}<0
$$

because:

$$
\frac{\left.\partial \chi(x)\right|_{\iota=1}}{\partial \gamma}=f\left(\frac{\Delta}{[\gamma c+\iota \sigma s(x)]^{\delta}}\right)\left(-\frac{\Delta \delta c}{[\gamma c+\sigma s(x)]^{\delta+1}}\right)<0 .
$$

The effect of an increase in the cost of infection, $c$, on the equilibrium under the state of emergency, $x_{\text {under }}^{*}$, is given by:

$$
\frac{d x_{\mathrm{under}}^{*}}{d c}=\frac{\frac{\left.\partial \chi(x)\right|_{\iota=1}}{\partial c}}{1-\frac{\left.\partial \chi(x)\right|_{\iota=1}}{\partial x}}<0
$$

because:

$$
\frac{\left.\partial \chi(x)\right|_{\iota=1}}{\partial c}=f\left(\frac{\Delta}{[\gamma c+\iota \sigma s(x)]^{\delta}}\right)\left(-\frac{\Delta \delta \gamma}{[\gamma c+\sigma s(x)]^{\delta+1}}\right)<0 .
$$

The effect of an increase in the relative size of the stigma to the infection in the psychological cost, $\sigma$, on the equilibrium under the state of emergency, $x_{\text {under }}^{*}$, is given by:

$$
\frac{d x_{\text {under }}^{*}}{d \sigma}=\frac{\frac{\left.\partial \chi(x)\right|_{\iota=1}}{\partial \sigma}}{1-\frac{\left.\partial \chi(x)\right|_{\iota=1}}{\partial x}}<0
$$

because:

$$
\frac{\left.\partial \chi(x)\right|_{\iota=1}}{\partial \sigma}=f\left(\frac{\Delta}{[\gamma c+\iota \sigma s(x)]^{\delta}}\right)\left(-\frac{\Delta \delta s(x)}{[\gamma c+\sigma s(x)]^{\delta+1}}\right)<0 .
$$

The effect of an increase in the level of the parameter of cost to scale, $\delta$, on the equilibrium under the state of emergency, $x_{\text {under }}^{*}$, is given by:

$$
\frac{d x_{\mathrm{under}}^{*}}{d \delta}=\frac{\frac{\left.\partial \chi(x)\right|_{\iota=1}}{\partial \delta}}{1-\frac{\left.\partial \chi(x)\right|_{\iota=1}}{\partial x}}<0
$$

because:

$$
\frac{\left.\partial \chi(x)\right|_{\iota=1}}{\partial \delta}=f\left(\frac{\Delta}{[\gamma c+\iota \sigma s(x)]^{\delta}}\right)\left(-\frac{\Delta \delta^{(\gamma c+\sigma s(x))} \ln \delta}{[\gamma c+\iota \sigma s(x)]^{2 \delta}}\right)<0 .
$$

Next, we conduct the comparative static analysis in the equilibrium after the state of emergency is lifted. Let us consider the effect of an increase in the level of the utility of going out, $u_{\text {out }}$, on the equilibrium after the state of emergency is lifted, $x_{\text {post }}^{*}$. The result is given by:

$$
\frac{d x_{\mathrm{post}}^{*}}{d u_{\mathrm{out}}}=f\left(\frac{\Delta}{(\gamma c)^{\delta}}\right)>0
$$


The effect of an increase in the level of the utility of staying home, $u_{\text {home, }}$ on the equilibrium after the state of emergency is lifted, $x_{\text {post }}^{*}$, is given by:

$$
\frac{d x_{\text {post }}^{*}}{d u_{\text {home }}}=-f\left(\frac{\Delta}{(\gamma c)^{\delta}}\right)<0 .
$$

The effect of an increase in the subjective probability of an individual being infected after going out, $\gamma$, on the equilibrium after the state of emergency is lifted, $x_{\text {post }}^{*}$, is given by:

$$
\frac{d x_{\text {post }}^{*}}{d \gamma}=f\left(\frac{\Delta}{(\gamma c)^{\delta}}\right)\left[-\frac{\Delta \delta c}{(\gamma c)^{\delta+1}}\right]<0 .
$$

The effect of an increase in the cost of infection, $c$, on the equilibrium after the state of emergency is lifted, $x_{\text {post }}^{*}$, is given by:

$$
\frac{d x_{\mathrm{post}}^{*}}{d c}=f\left(\frac{\Delta}{(\gamma c)^{\delta}}\right)\left[-\frac{\Delta \delta \gamma}{(\gamma c)^{\delta+1}}\right]<0 .
$$

The effect of the relative size of the stigma to the infection in the psychological cost, $\sigma$, on the equilibrium after the state of emergency is lifted, $x_{\text {post }}^{*}$, is zero because:

$$
\frac{d x_{\text {post }}^{*}}{d \sigma}=0 .
$$

The effect of an increase in the parameter of cost to scale, $\delta$, on the equilibrium after the state of emergency is lifted, $x_{\text {post }}^{*}$, is given by:

$$
\frac{d x_{\text {post }}^{*}}{d \delta}=f\left(\frac{\Delta}{(\gamma c)^{\delta}}\right)\left[-\frac{\Delta \delta^{(\gamma c)} \ln \delta}{(\gamma c)^{2 \delta}}\right]<0 .
$$

Proposition 4 shows natural results. The effect of an increase in the utility from going out on the proportion of players is positive in both equilibria $x_{\text {under }}^{*}$ and $x_{\text {post }}^{*}$. This result is because of the increased incentive to go out. By contrast, the effect of an increase in the utility of staying home on the proportion of players going out is negative in both equilibria. This result is because of the decreased incentive to go out. Similarly, the subjective probability of an individual being infected after going out, the cost of infection, the relative size of the stigma to the infection in the psychological cost, and the parameter of cost to scale have negative effects on the proportion of players going out. However, the relative size of the stigma to the infection in the psychological cost has no effect on the $x_{\text {post }}^{*}$ because there is no stigma in the equilibrium.

\section{Empirical Analysis}

This section analyzes how Japan's unenforceable emergency declarations triggered by COVID-19 affected people's going-out behavior using daily prefectural population flow data from the Google COVID-19 Community Mobility Reports as well as several covariates. In addition, we analyze how the behavior of people who went out after the state of emergency was lifted changed compared with that before it was issued, that is, whether the effects of the declaration continued after the emergency was lifted. 


\section{Methodology}

In this study, we analyze the effects of emergency declarations on people's going-out behavior using a panel data model. Specifically, the following one-way error component model (Baltagi 1984) is used:

$$
\begin{aligned}
& y_{i t}=\mathbf{x}_{i t}^{\prime} \boldsymbol{\beta}+e_{i t}, \\
& e_{i t}=\alpha_{i}+v_{i t},
\end{aligned}
$$

where $y$ is the dependent variable of human flow, $i=1, \ldots, n$ is the index for the $i$ th prefecture, $t=1, \ldots, T$ is the date, $\mathbf{x}$ is an explanatory variable vector containing covariates, $\boldsymbol{\beta}$ is an unknown parameter vector, and $e$ is the disturbance term. Furthermore, as in Equation 34, the disturbance term can be decomposed into stochastic variability $v$ and prefecture-level heterogeneity $\alpha$. Furthermore, focusing on the explanatory variable vector, it is decomposed as follows:

$$
\mathbf{x}_{i t}:=\left[\mathbf{d}_{i t}^{\prime}, \mathbf{w}_{i t}^{\prime}\right]^{\prime},
$$

where $\mathbf{d}_{i t}$ is a vector of target variables consisting of two dummy variables, one for the date under the declaration and one for the date after the declaration, and $\mathbf{w}_{i t}$ is a covariate vector.

The model in Equation (34) can be estimated using a one-way fixed-effect estimator (hereinafter, one-way FE) and a one-way random-effect estimator (hereinafter, one-way $\mathrm{RE}$ ). The one-way FE presumes a binary dummy variable for $\alpha_{i}$, whereas the one-way RE assumes that the individual effect is randomly determined. In this study, we estimate both and examine the estimates adopted as a result of the Hausman test.

\section{Data}

This study measures the effect of unenforceable emergency declarations on people's goingout behavior in Japan. For this purpose, we constructed a daily panel dataset at the prefecture level. In this section, we describe the contents of the data in detail.

First, we discuss the dependent variable $y_{i t}$ described in Methodology, namely, goingout behavior, which is the subject of the effects of policy interventions. This study uses the Google COVID-19 Community Mobility Reports ${ }^{3}$ to evaluate the effect of the data on people's going-out behavior across Japan. Google collected these data to provide evidence on how public health authorities respond to COVID-19. These data are anonymized and aggregated with an emphasis on protecting people's privacy by using only location information from applications such as Google Maps ${ }^{4}$; in other words, the data are summarized by region. In Japan, approximately $90 \%$ of people have used map applications at least once, and the number of Google Maps users is approximately $80 \%$ based on a survey ${ }^{5}$. Therefore, anonymized aggregate data obtained from users' Google Maps location data are considered reliable in terms of representing human flows in all prefectures of Japan. In addition, these data are divided into six categories according to the content of the goingout behavior: "Retail \& recreation," "Grocery \& pharmacy," "Parks," "Transit stations," "Workplaces," and "Residential." In this study, four of these six categories, "Retail \& recreation" (retail), "Grocery \& pharmacy" (grocery), "Parks" (park), and "Workplaces"

\footnotetext{
${ }^{3}$ https://www.google.com/covid19/mobility/, accessed on July 10, 2020

${ }^{4}$ https://www.google.co.jp/maps/, accessed on July 10, 2020

${ }^{5}$ https://www.value-press.com/pressrelease/215276, in Japanese, accessed on July 10, 2020
} 
(workplace), are used as dependent variables in terms of measuring the effect of emergency declarations based on the purpose of going out. According to the Google COVID-19 Community Mobility Reports, retail refers to going-out behavior consisting of entertainment and leisure-time purchases at restaurants, cafes, shopping centers, theme parks, museums, libraries, cinemas, and so forth. grocery refers to going-out behavior for activities related to purchasing daily necessities, such as visiting grocery stores, food wholesalers, fruit and vegetable markets, luxury grocery stores, drug stores, pharmacies, and so forth. park refers to going out to a park, such as a regional park, national park, public beach, marina, dog park, square, garden, and so forth. Finally, workplace refers to going-out behavior related to workplace commuting. In addition, it is important to note that these movement data are presented as percentage changes from the baseline value for each of the seven days of the week. These baseline values are defined by the median value for each of the seven days of the week during the five-week period from January 3 to February 6, 2020.

Second, we discuss variables that make up the target explanatory variable, $\mathbf{d}_{i t}$. This vector comprises variables that measure the status of the emergency declaration. Therefore, we use the following variables as target variables in this study: the first is under that equals one on dates under the state of emergency and 0 otherwise, and the second is post that equals one on dates after the state of emergency was lifted and 0 otherwise. The dates on which the state of emergency was declared and was lifted differ from prefecture to prefecture. In this study, we use date range data on the emergency declarations in Japan (Katafuchi 2020) based on reports published by the Office for Novel Coronavirus Disease Control, Cabinet Secretariat, Government of Japan.

Third, we describe a covariate vector $\mathbf{w}_{i t}$. As mentioned earlier, the dependent variable in this dataset is represented by the disparity from the seven reference values on each day of the week. Therefore, it is possible that there are seasonal differences between the five weeks within which these reference values are defined and the sample. In this study, the two weather variables, daily precipitation (precipitation) and daily sunshine hours (sunlight), are obtained from the Japan Meteorological Agency ${ }^{6}$, and are used to control for its seasonality. The positional attributes of these data are defined by a more detailed classification than at the prefecture-level. Therefore, in this study, we treat meteorological data from the prefectural capitals as prefecture-level meteorological data to ensure representativeness. Furthermore, we consider that the effect of the spread of COVID-19, that is, the subjective probability of contracting the disease, on people's going-out behavior is present, as also incorporated in the theoretical model in Theoretical Model. Therefore, it is necessary to control the situation of infection at the prefecture-level. This study thus incorporates a one-period lag of the increase in the number of infected people per million (inc_positive_perm) into the covariate vector. These data are calculated using the data from TOYO KEIZAI ONLINE (2020). However, because the data period begins from March 11, 2020, the data before that date were compiled based on press releases by the Ministry of Health, Labor and Welfare, Japan ${ }^{7}$.

Finally, we discuss how we determined the sample period for this dataset. Table 1 shows when the state of emergency was declared (emergency_start) and lifted (emergency_end) for each prefecture, as well as the period during which the state of emergency was declared (emergency_length). The length of time under the emergency

\footnotetext{
${ }^{6}$ https://www.data.jma.go.jp/obd/stats/etrn/index.php, in Japanese, accessed on July 10, 2020

${ }^{7}$ https://www.mhlw.go.jp/stf/seisakunitsuite/bunya/0000121431_00086.html, in Japanese, accessed on July 10,2020
} 
Table 1 Date and length of state of emergency in the prefectures of Japan

\begin{tabular}{|c|c|c|c|}
\hline prefecture & emergency_start & emergency_end & emergency_length \\
\hline Hokkaido & 2020-04-16 & $2020-05-25$ & 39 \\
\hline Aomori & $2020-04-16$ & $2020-05-14$ & 28 \\
\hline Iwate & $2020-04-16$ & $2020-05-14$ & 28 \\
\hline Miyagi & $2020-04-16$ & $2020-05-14$ & 28 \\
\hline Akita & 2020-04-16 & $2020-05-14$ & 28 \\
\hline Yamagata & $2020-04-16$ & $2020-05-14$ & 28 \\
\hline Fukushima & 2020-04-16 & $2020-05-14$ & 28 \\
\hline Ibaraki & $2020-04-16$ & $2020-05-14$ & 28 \\
\hline Tochigi & 2020-04-16 & $2020-05-14$ & 28 \\
\hline Gunma & 2020-04-16 & $2020-05-14$ & 28 \\
\hline Saitama & 2020-04-07 & $2020-05-25$ & 48 \\
\hline Chiba & 2020-04-07 & $2020-05-25$ & 48 \\
\hline Tokyo & 2020-04-07 & $2020-05-25$ & 48 \\
\hline Kanagawa & 2020-04-07 & $2020-05-25$ & 48 \\
\hline Niigata & 2020-04-16 & $2020-05-14$ & 28 \\
\hline Toyama & 2020-04-16 & $2020-05-14$ & 28 \\
\hline Ishikawa & $2020-04-16$ & $2020-05-14$ & 28 \\
\hline Fukui & $2020-04-16$ & $2020-05-14$ & 28 \\
\hline Yamanashi & 2020-04-16 & $2020-05-14$ & 28 \\
\hline Nagano & $2020-04-16$ & $2020-05-14$ & 28 \\
\hline Gifu & $2020-04-16$ & $2020-05-14$ & 28 \\
\hline Shizuoka & $2020-04-16$ & $2020-05-14$ & 28 \\
\hline Aichi & $2020-04-16$ & $2020-05-14$ & 28 \\
\hline Mie & 2020-04-16 & $2020-05-14$ & 28 \\
\hline Shiga & $2020-04-16$ & $2020-05-14$ & 28 \\
\hline Kyoto & 2020-04-16 & $2020-05-21$ & 35 \\
\hline Osaka & 2020-04-07 & $2020-05-21$ & 44 \\
\hline Hyogo & 2020-04-07 & $2020-05-21$ & 44 \\
\hline Nara & 2020-04-16 & $2020-05-14$ & 28 \\
\hline Wakayama & 2020-04-16 & $2020-05-14$ & 28 \\
\hline Tottori & 2020-04-16 & $2020-05-14$ & 28 \\
\hline Shimane & $2020-04-16$ & $2020-05-14$ & 28 \\
\hline Okayama & $2020-04-16$ & $2020-05-14$ & 28 \\
\hline Hiroshima & 2020-04-16 & $2020-05-14$ & 28 \\
\hline Yamaguchi & $2020-04-16$ & $2020-05-14$ & 28 \\
\hline
\end{tabular}

declaration varied from prefecture to prefecture - the shortest period was 28 days in approximately $80 \%$ of the prefectures. In this study, we use the mode value of the period under the emergency declaration to determine the length of the sample period under the state of emergency and after its lifting. Accordingly, this length is determined from the issuance to the cancellation of the state of emergency in large urban areas, such as Tokyo, Kanagawa, and Osaka, as these areas had longer emergency periods than most other regions. Therefore, we 
Table 1 (continued)

\begin{tabular}{llll}
\hline prefecture & emergency_start & emergency_end & emergency_length \\
\hline Tokushima & $2020-04-16$ & $2020-05-14$ & 28 \\
Kagawa & $2020-04-16$ & $2020-05-14$ & 28 \\
Ehime & $2020-04-16$ & $2020-05-14$ & 28 \\
Kochi & $2020-04-16$ & $2020-05-14$ & 28 \\
Fukuoka & $2020-04-07$ & $2020-05-14$ & 37 \\
Saga & $2020-04-16$ & $2020-05-14$ & 28 \\
Nagasaki & $2020-04-16$ & $2020-05-14$ & 28 \\
Kumamoto & $2020-04-16$ & $2020-05-14$ & 28 \\
Oita & $2020-04-16$ & $2020-05-14$ & 28 \\
Miyazaki & $2020-04-16$ & $2020-05-14$ & 28 \\
Kagoshima & $2020-04-16$ & $2020-05-14$ & 28 \\
Okinawa & $2020-04-16$ & $2020-05-14$ & 28 \\
\hline
\end{tabular}

define the sample period from April 7 to 28 days prior to the declaration of the state of emergency in these metropolitan areas - that is, March 10, 2020, is the starting point of the entire sample period. Conversely, this study defines the sample period from May 25 to 28 days after the lifting of the state of emergency for these metropolitan areas as the post-declaration sample period, with June 22, 2020 as the endpoint of the overall sample period. The sample is therefore composed of 47 prefectures, that is, $n=47$; the sample period is from March 10 to June 22, 2020, that is, $T=105$; and the sample size is $N=n T=47 \times 105=4,935$.

\section{Result}

First, we briefly look at the disparity between the going-out behavior in the pre-declaration, under declaration, and post-declaration periods. It must be noted that each of these disparities is defined by the difference from the representative value for the reference period defined by the Google COVID-19 Community Mobility Reports. Figure 2 shows the disparity for retail, that is, the difference from the reference value for the going-out purpose of purchasing activities related to entertainment and leisure, for the time period specified by the declaration of the state of emergency. To show the disparity more clearly by day of the week in this figure, we choose representative dates for each day of the week for each time period defined by the emergency declaration, so that the status of the emergency declaration is the same for all prefectures: March 28 (Saturday), March 29 (Sunday), and April 1 (Wednesday) for pre-declaration; April 25 (Saturday), April 26 (Sunday), and April 29 (Wednesday) for under declaration; and May 30 (Saturday), May 31 (Sunday), and June 3 (Wednesday) for post-declaration. To further reflect the status of infection in each prefecture, this figure groups the samples by the date of the end of the state of emergency and shows the different shapes of the points. The three panels on the left compare the going-out behavior for retail between flows before and under the emergency declaration, and the three panels on the right compare the flows for retail under the emergency and after it was lifted. The overall trend is that there is a bigger flow of people pre- and post-declaration than under declaration. In other words, the flow of people for retail under a declared state of emergency decreases. This is because almost all of the points are to the left of the 45-degree line. However, a comparison between Sundays before and under the emergency 

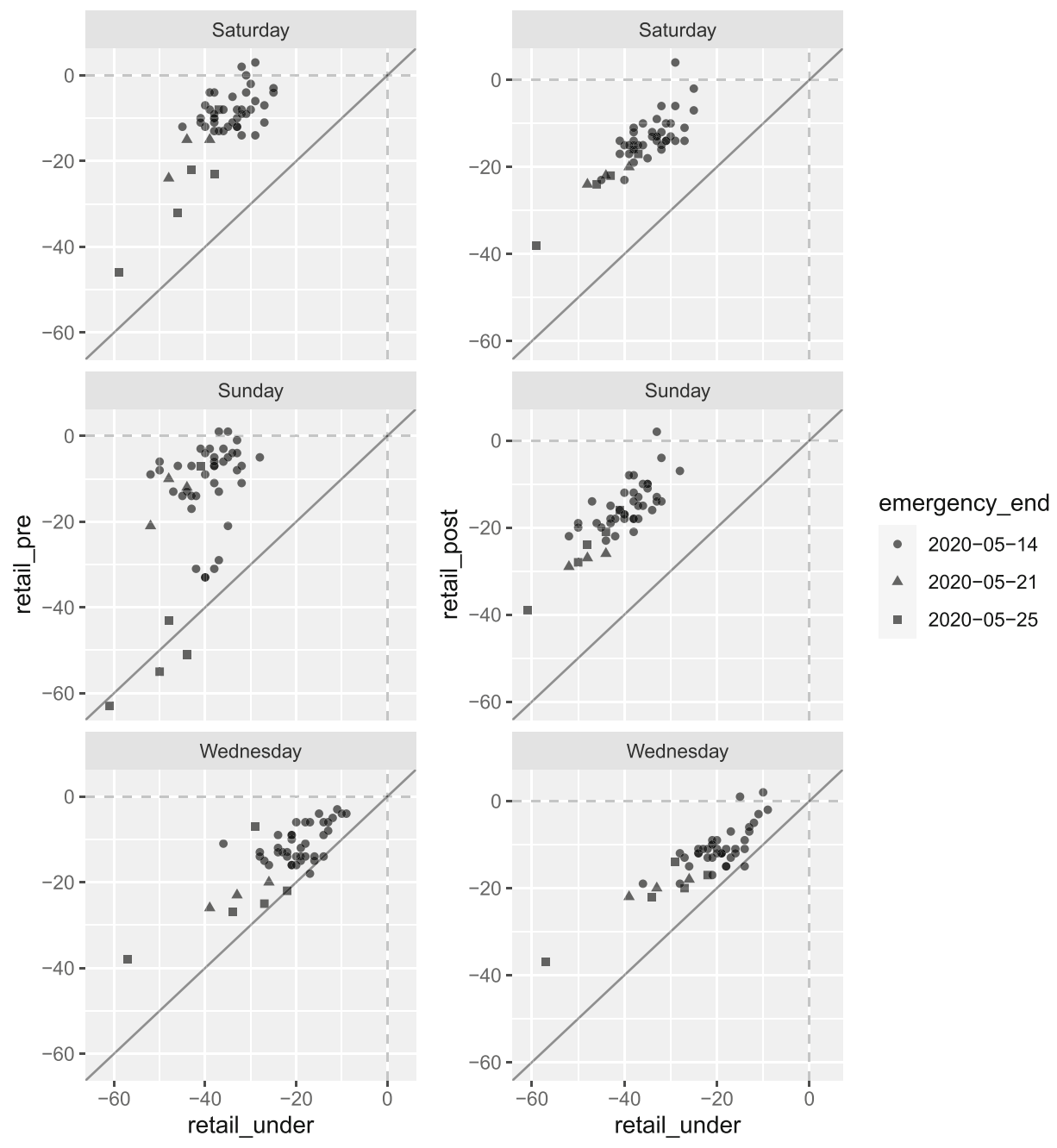

Fig. 2 Comparison of going-out behavior in Japan's prefectures: retail, Notes: The panels show the scatter plots of going-out behavior for retail between pre-declaration and under declaration (left) and post-declaration and under declaration (right) for three representative days: Saturday, Sunday, and Wednesday

declaration shows a slight increase in flows under the emergency declaration in some large cities such as Tokyo and Kanagawa in prefectures where the declaration was lifted at the latest.

Next, we look briefly at the disparity in human flows for grocery. Figure 3 shows the same overall trend as for retail, although the number of prefectures where the flow of people is higher in the under declaration than in the pre-declaration is higher here. As for parks, except for the Saturday after lifting the state of emergency and the Sunday before its lifting, the overall increase in the number of people going to parks under the emergency declaration can be seen in Fig. 4. Finally, for workplace, the trend is the same as for retail and grocery. Figure 5 shows that the number of people going out for 

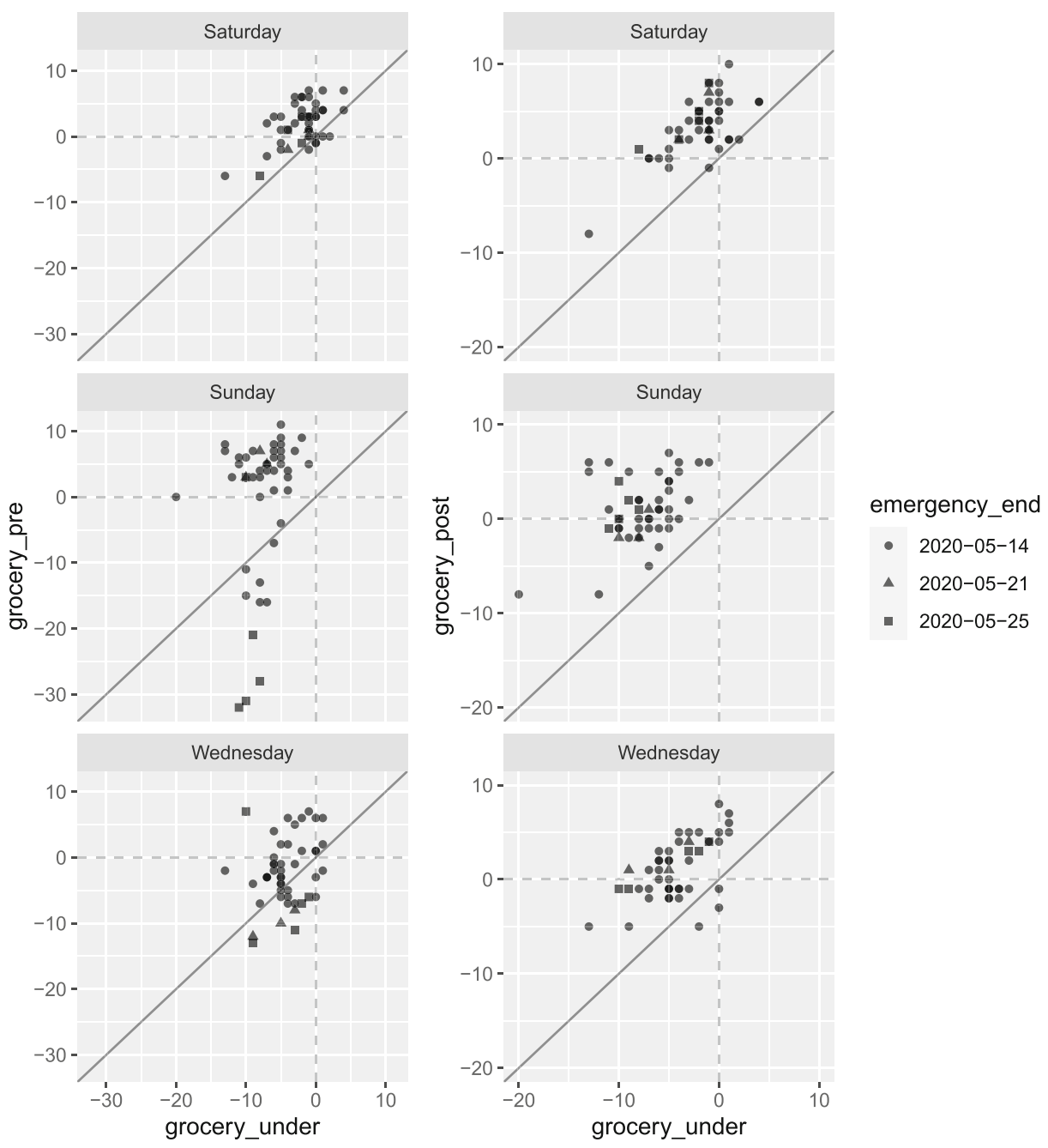

Fig. 3 Comparison of going-out behavior in Japan's prefectures: grocery, Notes: The panels show the scatter plots of going-out behavior for grocery between pre-declaration and under declaration (left) and post-declaration and under declaration (right) for three representative days: Saturday, Sunday, and Wednesday

work decreased on any day of the week under a declared emergency situation. This can be attributed to the people's semi-compulsory decision of not going out for work in response to the government's telecommute requirements. With the exception of park, the going-out behavior in all categories decreased under the declaration. However, an analysis controlling for seasonality is necessary for park; furthermore, this analysis fails to account for prefecture-level heterogeneity in going-out behavior. In this study, we estimate the panel data model described in Methodology and conduct in-depth analysis of how non-legally binding emergency declarations can affect going-out behavior.

Table 2 shows the results of estimating the panel data model introduced in Methodolo gy with the prefecture-level panel dataset created in this study. Each column represents a 

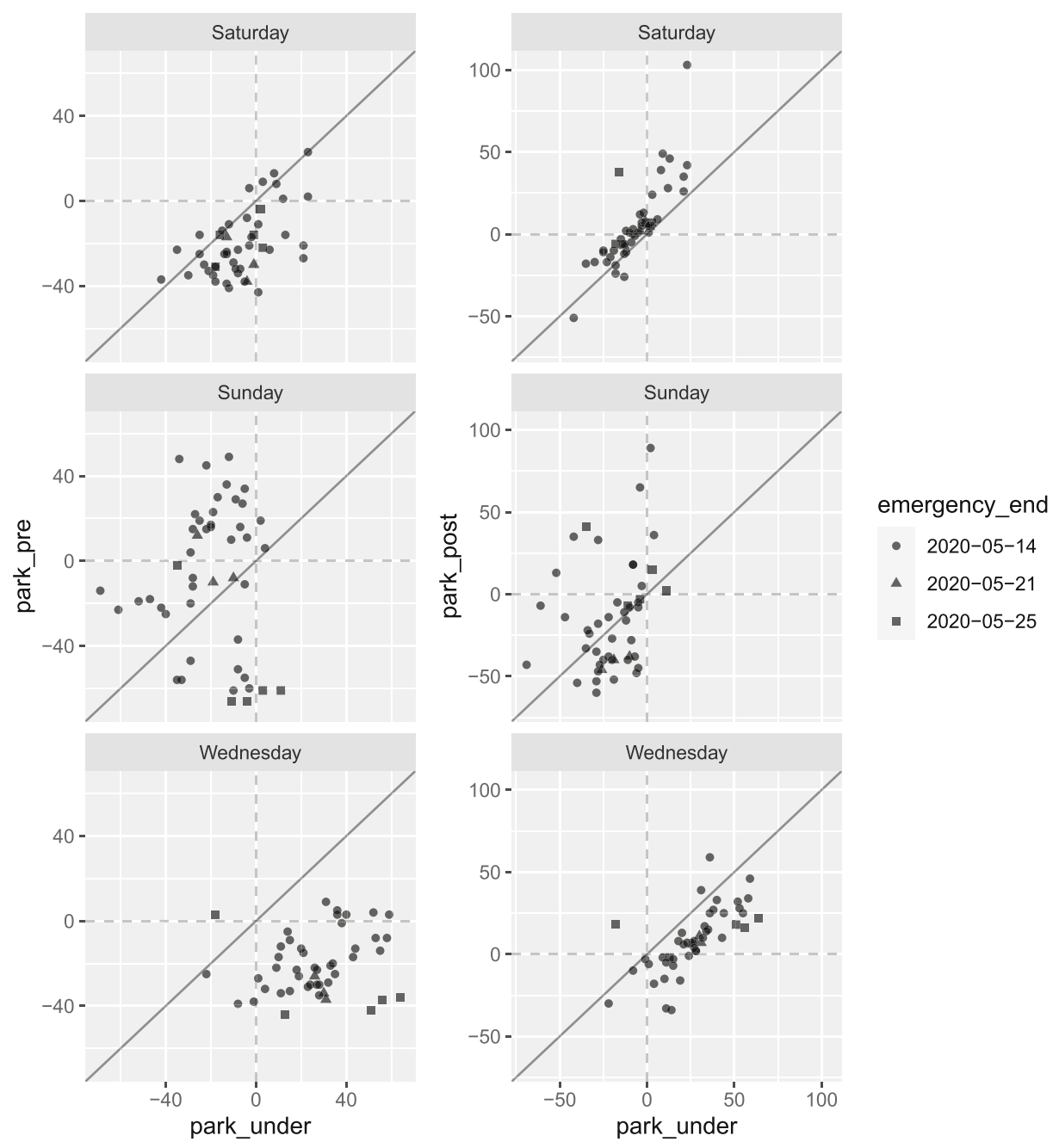

Fig. 4 Comparison of going-out behavior in Japan's prefectures: park, Notes: The panels show the scatter plots of going-out behavior for park between pre-declaration and under declaration (left) and postdeclaration and under declaration (right) for three representative days: Saturday, Sunday, and Wednesday

category of the dependent variable, the change in going-out behavior from the reference going out period. Following the rule that a fixed-effect estimator is used if the results of the Hausman test are less than 5\% statistically significant, a one-way fixed effect estimator is used in all categories except for park. This may be explained by the fact that heterogeneity at the prefectural level is randomly determined with respect to the going-out behavior for park, as seen in the scatter-plot analysis described above. The estimated coefficients are negative and statistically significant for all dependent variables, both under and post. Therefore, the results show that, comparing the periods before the emergency declaration and the reference value, going-out behavior decreased in both the under declaration and post-declaration periods. Furthermore, looking at the estimated magnitudes of the coefficients, under is smaller than post for all dependent variables. This phenomenon suggests 

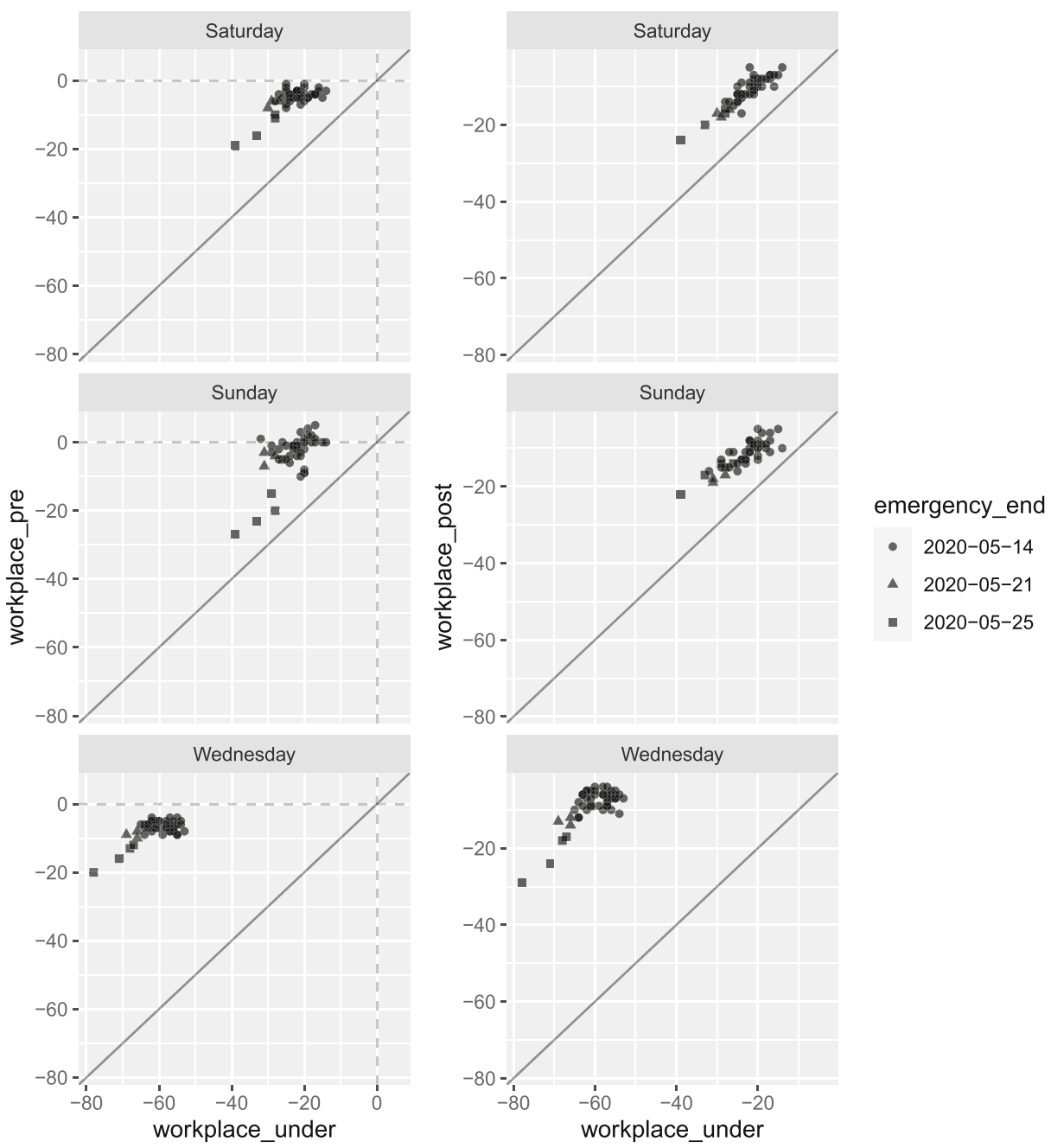

Fig. 5 Comparison of going-out behavior in the prefectures of Japan: workplace, Notes: The panels show the scatter plots of going-out behavior for workplace between pre-declaration and under declaration (left) and post-declaration and under declaration (right) for three representative days: Saturday, Sunday, and Wednesday

that under the state of emergency declaration, people may have been less likely to go out than post-declaration, based on the difference between their behaviors and the reference value before the emergency declaration.

To confirm the robustness of this relationship, this study conducts sensitivity analyses. First, results of the estimation with all covariates excluded are shown in Table 3. In this simpler estimation model, a one-way random effect estimator is used in the models for the three dependent variables except for workplace, following the rule that a fixed-effect estimator is used if the results of the Hausman test show that the statistical significance is less than 5\%. Therefore, it is desirable that heterogeneity at the prefectural level is randomly determined when no covariates are incorporated into the model. The estimation 
Table 2 Results of empirical analysis using mobility data

\begin{tabular}{|c|c|c|c|c|}
\hline & \multicolumn{4}{|c|}{ Dependent variable } \\
\hline & retail & grocery & park & workplace \\
\hline under & $\begin{array}{l}-19.955^{* * *} \\
(0.513)\end{array}$ & $\begin{array}{l}-5.578^{* * *} \\
(0.235)\end{array}$ & $\begin{array}{l}-12.884^{* * *} \\
(1.544)\end{array}$ & $\begin{array}{l}-18.182^{* * *} \\
(0.507)\end{array}$ \\
\hline post & $\begin{array}{l}-6.410^{* * *} \\
(0.387)\end{array}$ & $\begin{array}{l}-2.159^{* * *} \\
(0.199)\end{array}$ & $\begin{array}{l}-7.231^{* * *} \\
(1.770)\end{array}$ & $\begin{array}{l}-3.340^{* * *} \\
(0.325)\end{array}$ \\
\hline Constant & & & $\begin{array}{l}-6.067^{* * *} \\
(1.296)\end{array}$ & \\
\hline Observations & 4,935 & 4,935 & 4,935 & 4,935 \\
\hline$R^{2}$ & 0.588 & 0.488 & 0.533 & 0.335 \\
\hline Adjusted $R^{2}$ & 0.583 & 0.483 & 0.532 & 0.328 \\
\hline Hausman-test & $1513.3^{* * *}$ & $73.443^{* * *}$ & 3.393 & $114.81^{* * *}$ \\
\hline Estimator & $\mathrm{FE}$ & $\mathrm{FE}$ & $\mathrm{RE}$ & $\mathrm{FE}$ \\
\hline Covariates & Yes & Yes & Yes & Yes \\
\hline
\end{tabular}

Notes: Numbers in parentheses stand for clustered-robust standard errors. ${ }^{*},{ }^{* *}$, and ${ }^{* * *}$ indicate statistical significance at the $10 \%, 5 \%$, and $1 \%$ levels, respectively. FE=fixed effect; RE=random effect.

results, however, show the same tendency as in Table 2, which presents the estimation result with all covariates. Second, the results of the estimation using estimators, which are not adopted based on the rule of using a fixed-effect estimator if the results of the

Table 3 Results of empirical analysis using mobility data: sensitivity analysis without covariates

\begin{tabular}{|c|c|c|c|c|}
\hline & \multicolumn{4}{|c|}{ Dependent variable: } \\
\hline & retail & grocery & park & workplace \\
\hline under & $\begin{array}{l}-20.143^{* * *} \\
(0.640)\end{array}$ & $\begin{array}{l}-5.288^{* * *} \\
(0.245)\end{array}$ & $\begin{array}{l}-10.972^{* * *} \\
(1.460)\end{array}$ & $\begin{array}{l}-18.142^{* * *} \\
(0.526)\end{array}$ \\
\hline post & $\begin{array}{l}-5.925^{* * *} \\
(0.391)\end{array}$ & $\begin{array}{l}-2.600^{* * *} \\
(0.215)\end{array}$ & $\begin{array}{l}-9.664^{* * *} \\
(2.071)\end{array}$ & $\begin{array}{l}-3.368^{* * *} \\
(0.311)\end{array}$ \\
\hline Constant & $\begin{array}{l}-7.482^{* * *} \\
(0.546)\end{array}$ & $\begin{array}{l}3.005^{* * *} \\
(0.240)\end{array}$ & $\begin{array}{l}8.421^{* * *} \\
(1.231)\end{array}$ & \\
\hline Observations & 4,935 & 4,935 & 4,935 & 4,935 \\
\hline$R^{2}$ & 0.492 & 0.177 & 0.045 & 0.334 \\
\hline Adjusted $R^{2}$ & 0.492 & 0.177 & 0.045 & 0.327 \\
\hline Hausman-test & 4.586 & 0.093 & 0.045 & $21.868^{* * *}$ \\
\hline Estimator & $\mathrm{RE}$ & $\mathrm{RE}$ & $\mathrm{RE}$ & FE \\
\hline Covariates & No & No & No & No \\
\hline
\end{tabular}

Notes: Numbers in parentheses stand for clustered-robust standard errors. ${ }^{*}{ }^{* *}$, and ${ }^{* * *}$ indicate statistical significance at the $10 \%, 5 \%$, and $1 \%$ levels, respectively. $\mathrm{FE}=$ fixed effect; RE=random effect. 
Table 4 Results of empirical analysis using mobility data: sensitivity analysis using other estimators with covariates

\begin{tabular}{|c|c|c|c|c|}
\hline & \multicolumn{4}{|c|}{ Dependent variable: } \\
\hline & retail & grocery & park & workplace \\
\hline \multirow[t]{2}{*}{ under } & $-19.991^{* * *}$ & $-5.577^{* * *}$ & $-12.891^{* * *}$ & $-18.305^{* * *}$ \\
\hline & $(0.519)$ & $(0.236)$ & $(1.545)$ & $(0.525)$ \\
\hline \multirow[t]{2}{*}{ post } & $-6.446^{* * *}$ & $-2.162^{* * *}$ & $-7.232^{* * *}$ & $-3.452^{* * *}$ \\
\hline & $(0.392)$ & (0.199) & $(1.773)$ & $(0.347)$ \\
\hline \multirow[t]{2}{*}{ Constant } & $-8.138^{* * *}$ & $1.685^{* * *}$ & & $-7.925^{* * *}$ \\
\hline & $(0.545)$ & $(0.281)$ & & $(0.354)$ \\
\hline Observations & 4,935 & 4,935 & 4,935 & 4,935 \\
\hline$R^{2}$ & 0.585 & 0.486 & 0.536 & 0.336 \\
\hline Adjusted $R^{2}$ & 0.585 & 0.485 & 0.531 & 0.335 \\
\hline Hausman-test & $1513.3^{* * *}$ & $73.443^{* * *}$ & 3.393 & $114.81^{* * *}$ \\
\hline Estimator & $\mathrm{RE}$ & $\mathrm{RE}$ & $\mathrm{FE}$ & $\mathrm{RE}$ \\
\hline Covariates & Yes & Yes & Yes & Yes \\
\hline
\end{tabular}

Notes: Numbers in parentheses stand for clustered-robust standard errors. ${ }^{*},{ }^{* *}$, and ${ }^{* * *}$ indicate statistical significance at the $10 \%, 5 \%$, and $1 \%$ levels, respectively. FE=fixed effect; RE=random effect.

Hausman test showed less than 5\% statistical significance, are shown in Table 4 when all covariates are included and in Table 5 when all covariates are excluded. In these results, the coefficients are similar to those in Tables 2 and 3, that is, fewer individuals going out

Table 5 Results of empirical analysis using mobility data: sensitivity analysis using other estimators without covariates

\begin{tabular}{|c|c|c|c|c|}
\hline & \multicolumn{4}{|c|}{ Dependent variable: } \\
\hline & retail & grocery & park & workplace \\
\hline \multirow[t]{2}{*}{ under } & $-20.101^{* * *}$ & $-5.286^{* * *}$ & $-10.977^{* * *}$ & $-18.272^{* * *}$ \\
\hline & $(0.630)$ & $(0.245)$ & $(1.464)$ & $(0.555)$ \\
\hline \multirow[t]{2}{*}{ post } & $-5.926^{* * *}$ & $-2.600^{* * *}$ & $-9.665^{* * *}$ & $-3.364^{* * *}$ \\
\hline & $(0.390)$ & $(0.215)$ & $(2.070)$ & $(0.310)$ \\
\hline \multirow[t]{2}{*}{ Constant } & & & & $-7.572^{* * *}$ \\
\hline & & & & $(0.300)$ \\
\hline Observations & 4,935 & 4,935 & 4,935 & 4,935 \\
\hline$R^{2}$ & 0.495 & 0.178 & 0.046 & 0.334 \\
\hline Adjusted $R^{2}$ & 0.490 & 0.170 & 0.036 & 0.333 \\
\hline Hausman-test & 4.586 & 0.093 & 0.045 & $21.868^{* * *}$ \\
\hline Estimator & $\mathrm{FE}$ & $\mathrm{FE}$ & $\mathrm{FE}$ & $\mathrm{RE}$ \\
\hline Covariates & No & No & No & No \\
\hline
\end{tabular}

Notes: Numbers in parentheses stand for clustered-robust standard errors. ${ }^{* *}$, and $* * *$ indicate statistical significance at the $10 \%, 5 \%$, and $1 \%$ levels, respectively. FE=fixed effect; RE=random effect. 
Table 6 Results of empirical analysis using mobility data: sensitivity analysis using a subset of the sample with the earliest state of emergency declaration

\begin{tabular}{|c|c|c|c|c|}
\hline & \multicolumn{4}{|c|}{ Dependent variable: } \\
\hline & retail & grocery & park & workplace \\
\hline \multirow[t]{2}{*}{ under } & $-25.005^{* * *}$ & $-6.341^{* * *}$ & $-9.888^{* * *}$ & $-23.756^{* * *}$ \\
\hline & $(1.312)$ & $(0.588)$ & (1.016) & $(0.729)$ \\
\hline \multirow[t]{2}{*}{ post } & $-10.002^{* * *}$ & $-2.826^{* * *}$ & $-11.053^{* * *}$ & $-7.739^{* * *}$ \\
\hline & $(1.051)$ & $(0.590)$ & $(0.830)$ & $(0.846)$ \\
\hline \multirow[t]{2}{*}{ Constant } & $-12.034^{* * *}$ & & & \\
\hline & (2.199) & & & \\
\hline Observations & 735 & 735 & 735 & 735 \\
\hline$R^{2}$ & 0.734 & 0.627 & 0.669 & 0.485 \\
\hline Adjusted $R^{2}$ & 0.733 & 0.621 & 0.664 & 0.477 \\
\hline Hausman-test & $11.020^{*}$ & $34.235^{* * *}$ & $467.020^{* * *}$ & $1083.000^{* * *}$ \\
\hline Estimator & $\mathrm{RE}$ & FE & FE & FE \\
\hline Covariates & Yes & Yes & Yes & Yes \\
\hline
\end{tabular}

Notes: Numbers in parentheses stand for clustered-robust standard errors. ${ }^{*},{ }^{* *}$, and ${ }^{* * *}$ indicate statistical significance at the $10 \%, 5 \%$, and $1 \%$ levels, respectively. FE=fixed effect; RE=random effect.

in the under and post declaration periods than before the declaration of the state ofemergency. Moreover, the most self-restraint was shown under the declaration of the state of emergency. Third, Tables 6 and 7 show the results of each estimation in a sample of 47

Table 7 Results of empirical analysis using mobility data: sensitivity analysis using a subset of the sample without the earliest state of emergency declaration

\begin{tabular}{|c|c|c|c|c|}
\hline & \multicolumn{4}{|c|}{ Dependent variable: } \\
\hline & retail & grocery & park & workplace \\
\hline \multirow[t]{2}{*}{ under } & $-19.195^{* * *}$ & $-5.480^{* * *}$ & $-13.666^{* * *}$ & $-17.247^{* * *}$ \\
\hline & $(0.484)$ & $(0.263)$ & (1.798) & $(0.429)$ \\
\hline \multirow[t]{2}{*}{ post } & $-5.982^{* * *}$ & $-2.124^{* * *}$ & $-6.863^{* * *}$ & $-2.715^{* * *}$ \\
\hline & $(0.389)$ & $(0.213)$ & $(2.037)$ & $(0.232)$ \\
\hline \multirow[t]{2}{*}{ Constant } & $-7.342^{* * *}$ & & $-6.383^{* * *}$ & \\
\hline & $(0.419)$ & & (1.404) & \\
\hline Observations & 4,200 & 4,200 & 4,200 & 4,200 \\
\hline$R^{2}$ & 0.552 & 0.487 & 0.513 & 0.308 \\
\hline Adjusted $R^{2}$ & 0.552 & 0.481 & 0.513 & 0.301 \\
\hline Hausman-test & $4.315^{*}$ & $29.896^{* * *}$ & 0.2385 & $17.459^{* * *}$ \\
\hline Estimator & $\mathrm{RE}$ & $\mathrm{FE}$ & $\mathrm{RE}$ & $\mathrm{FE}$ \\
\hline Covariates & Yes & Yes & Yes & Yes \\
\hline
\end{tabular}

Notes: Numbers in parentheses stand for clustered-robust standard errors. ${ }^{*},{ }^{* *}$, and ${ }^{* * *}$ indicate statistical significance at the $10 \%, 5 \%$, and $1 \%$ levels, respectively. FE=fixed effect; RE=random effect. 
prefectures divided into two subsets: one $(N=n T=7 \times 105=735)$ consisting of the seven prefectures where a state of emergency was declared the earliest on April 7, 2020 (Saitama, Chiba, Tokyo, Kanagawa, Osaka, Hyogo, and Fukuoka), as shown in Table 1, and the other $(N=n T=40 \times 105=4,200)$ consisting of the remaining 40 prefectures where the state of emergency was not issued on this date. The estimators used are based on the rule that a fixed-effect estimator is used if the results of the Hausman test show that the statistical significance is less than 5\%. These results reinforce the findings that for both the seven prefectures with the earliest emergency declaration and the other 40 prefectures, there was less going-out behavior under and post declaration than before the declaration. Moreover, the most significant self-restraint behavior was observed under the declaration, except for the estimated result for the seven prefectures that there was less going-out behavior for park after the emergency was lifted than under the declaration. These sensitivity analyses indicate that the phenomenon of a statistically significant negative coefficient for under and post and a smaller coefficient for under than for post is robust.

This section confirmed the following: Going-out behavior was reduced both under the emergency declaration and after the emergency was lifted compared with before the declaration of the state of emergency; in addition, going-out behavior was most suppressed under the emergency declaration. This result clarifies two findings: First, people refrained from going out both under the declaration and after the lifting of the state of emergency. Second, despite the non-legally binding emergency declarations, people were more likely to refrain from going out under the declaration of a state of emergency than after it was lifted. Therefore, this second finding in the empirical analysis is consistent with Proposition 2 of the theoretical analysis in Theoretical Model. This suggests that under a declared state of emergency, people may have acted because of the stigma of going out as well as the risk of infection.

\section{Conclusion}

This study analyzes the effects of non-legally binding policies on going-out behavior from two perspectives: the construction of a micro-theoretical model and an empirical analysis using panel data from the Google COVID-19 Community Mobility Reports.

A plausible reason for the declaration's effectiveness is that people considered the risk of infection to be high. If this were the only reason, then the effect of restraint should be consistent when the risk of infection is constant under the declaration of an emergency and after it is lifted. The theoretical analysis of this study assumes that under a declared state of emergency, an individual going out suffers psychological costs arising from both the risk of infection and the stigma of going out. As a result, we showed that under a declared state of emergency, going out entails a strong psychological cost and people refrain from it (Proposition 2).

Using a panel dataset consisting of date data on the Japanese emergency declaration and daily human flow data as well as various covariates, the empirical analysis revealed two points. First, the flow of people under the declaration of a state of emergency was suppressed. Second, although the effect of the restraint continued after the state of emergency was lifted, the degree of restraint was greater under the state of emergency.

As the number of infected people in Japan is increasing again, there is a possibility that another state of emergency will be declared. In terms of policy action in such circumstances, the results of this study provide one policy implication by highlighting that non-legally 
binding policies can be effective in terms of reducing the number of people infected, that is, by curtailing their going-out behavior.

This study suggests the possibility of multiple equilibria- a strictly self-restraint equilibrium and not-strictly self-restraint equilibrium. In both equilibria, declaring a state of emergency has the effect of reducing the number of people going out, but the degree of effect may vary significantly. If there are multiple equilibria, then while the strictly self-restraint equilibrium was realized in Japan in reality, the not-strictly self-restraint equilibrium could also have been realized.

Hence, there is no guarantee that the effect of an emergency declaration will always be the same because it is generally not possible to know a priori which equilibrium will actually be realized as in the game with multiple equilibria. Therefore, it is likely that non-legally binding policies would need to be revised in favor of more legally binding policies to achieve a more accurate policy outcome in the fight against COVID-19.

\section{References}

Acemoglu D, Chernozhukov V, Werning I, Whinston MD (2020) A multi-risk sir model with optimally targeted lockdown. NBER Working Paper. https://www.nber.org/papers/w27102, (Accessed on July 11, 2020)

Alvarez FE, Argente D, Lippi F (2020) A simple planning problem for covid-19 lockdown. NBER Working Paper. https://www.nber.org/papers/w26981, (Accessed on July 11, 2020)

Aum S, Lee SYT, Shin Y (2020) Inequality of fear and self-quarantine: Is there a trade-off between gdp and public health? NBER Working Paper. https://www.nber.org/papers/w27100, (Accessed on July 11, 2020)

Baltagi BH (1984) A Monte Carlo Study for Pooling Time Series of Cross-Section Data in the Simultaneous Equations Model. Int Econ Rev 25(3):603-624

BBC (2020) Coronavirus: How did Florida get so badly hit by Covid-19?. https://www.bbc.com/news/ world-us-canada-53357742 (Accessed on August 4, 2020)

Besley T, Coate S (1992) Understanding welfare stigma: Taxpayer resentment and statistical discrimination. J Public Econ 48:165-183

Bhargava S, Manoli D (2015) Psychological Frictions and the Incomplete Take-Up of Social Benefits: Evidence from an IRS Field Experiment. Am Econ Rev 105(11):3489-3529

Bloomberg (2020) Covid-19 reinvades U.S. states that beat it back once. https://www.bloomberg.com/ news/articles/2020-07-13/covid-19-reinvades-u-s-states-that-already-beat-it-back-once (Accessed on August 4, 2020)

Eichenbaum MS, Rebelo S, Trabandt M (2020) The macroeconomics of testing and quarantining. NBER Working Paper. https://www.nber.org/papers/w27104, (Accessed on July 11, 2020)

Farboodi M, Jarosch G, Shimer R (2020) Internal and external effects of social distancing in a pandemic. NBER Working Paper. https://www.nber.org/papers/w27059, (Accessed on July 11, 2020)

Gharehgozli O, Nayebvali P, Gharehgozli A, Zamanian Z (2020) Impact of COVID-19 on the economic output of the US outbreak's epicenter. Economics of Disasters and Climate Change

Goffman E (1963) Stigma: Notes on the Management of Spoiled Identity, Prentice-Hall

Holtemöller O (2020) Integrated assessment of epidemic and economic dynamics. IWH Discussion Papers. https://www.econstor.eu/bitstream/10419/215895/1/1694465632.pdf, (Accessed on July 11, 2020)

Itaya J, Kurita K (2020) Replicator evolution of welfare stigma: Welfare fraud vs incomplete take-up. Mimeo

Iwasaki A, Grubaugh ND (2020) Why does japan have so few cases of covid-19? EMBO Molecular Medicine 12(5):e12481

Katafuchi Y (2020) covid-19_emergency_statement_japan. https://github.com/yuya-katafuchi/covid-19_ emergency_statement_japan (Accessed on July 11, 2020)

Kawaguchi K, Kodama N, Tanaka M (2020) Small business under the covid-19 crisis: Expected short-and medium-run effects of anti-contagion and economic policies. Available at SSRN 3634544

Kim Y (2003) Income distribution and equilibrium multiplicity in a stigma-based model of tax evasion. J Public Econ 87(7-8):1591-1616

Kobayashi G, Sugasawa S, Tamae H, Ozu T (2020) Predicting intervention effect for covid-19 in japan: state space modeling approach. BioScience Trends 
Kurita K, Hori N, Katafuchi Y (2020) Stigma model of welfare fraud and non-take-up: Theory and evidence from OECD panel data. Int J Econ Theory (Forthcoming)

Kyodo News (2020) Morning crowds down 60\% in central Tokyo after emergency declared. https://english.kyodonews.net/news/2020/04/4394741a8810-morning-crowds-down-60-in-central-tokyoafter-emergency-declared.html (Accessed on July 11, 2020)

Lindbeck A, Nyberg S, Weibull JW (1999) Social norms and economic incentives in the welfare state. The Quarterly Journal of Economics 114(1):1-35

Lindbeck A, Nyberg S, Weibull JW (2003) Social norms and welfare state dynamics. J Eur Econ Assoc 1(2-3):533-542

Lu N, Cheng K-W, Qamar N, Huang K-C, Johnson JA (2020) Weathering covid-19 storm: successful control measures of five asian countries. Am J Infect Control 48(7):851-852

Major B, Dovidio JF, Link BG (2018) The Oxford handbook of stigma, discrimination, and health. Oxford University Press, Oxford

Mandel A, Veetil V (2020) The economic cost of COVID lockdowns: An out-of-equilibrium analysis. Economics of Disasters and Climate Change

Martin A, Markhvida M, Hallegatte S, Walsh B (2020) Socio-economic impacts of COVID-19 on household consumption and poverty. Economics of Disasters and Climate Change

Moffitt R (1983) An economic model of welfare stigma. American economic review 73(5):1023-1035

Nakamura H, Managi S (2020) Airport risk of importation and exportation of the covid-19 pandemic. Transp Policy 96:40-47

Qian K, Yahara T (2020) Mentality and behavior in covid-19 emergency status in japan: Influence of personality, morality and ideology. PloS one 15(7):e0235883

Rasmusen E (1996) Stigma and self-fulfilling expectations of criminality. The Journal of Law and Economics 39(2):519-543

The Japan Times (2020) Japan cautiously lifts last of virus emergency controls. https://www.japantimes.co. jp/news/2020/05/25/national/japan-lifts-state-of-emergency-coronavirus/ (Accessed on July 11, 2020)

The Japan Times (2020) Japan's 'virus vigilantes' take on rule-breakers and invaders. https://www. japantimes.co.jp/news/2020/05/13/national/coronavirus- vigilantes-japan/ (Accessed on July 11, 2020)

The Japan Times (2020) Understanding the need to shame someone on social media for not exercising selfrestraint during a pandemic. https:/www.japantimes.co.jp/news/2020/05/16/national/media-national/ social-media-shaming-coronavirus/ (Accessed on July 11, 2020)

TOYO KEIZAI ONLINE (2020) Coronavirus disease (covid-19) situation report in japan. https://github.com/ kaz-ogiwara/covid19/blob/master/README.en.md (Accessed on July 11, 2020)

WHO (2020) Coronavirus disease 2019 (covid-19): situation report, 209. https://www.who.int/docs/ default-source/coronaviruse/situation-reports/20200816-covid-19-sitrep-209.pdf?sfvrsn=5dde1ca2_2 (Accessed on August 16, 2020)

Yamamoto T, Uchiumi C, Suzuki N, Yoshimoto J, Murillo-Rodriguez E (2020) The psychological impact of 'mild lockdown' in japan during the covid-19 pandemic: a nationwide survey under a declared state of emergency. medRxiv preprint medRxiv:2020.07.17.20156125

Yamamura E, Tsutsui Y (2020) Impact of the state of emergency declaration for covid-19 on preventive behaviors and mental conditions in japan: Difference in difference analysis using panel data. arXiv preprint arXiv:2005.13008

Yoo S, Managi S (2020) Global mortality benefits of covid-19 action. Technol Forecast Soc Chang

Publisher's Note Springer Nature remains neutral with regard to jurisdictional claims in published maps and institutional affiliations. 